Rev Biomed 2006; 17:140-145.

\title{
Control y poder en época de enfermedades. El cólera morbus de 1833 y el pueblo de Bolonchenticul, Península de Yucatán, México.
}

\author{
Historia de la Medicina
}

Laura Machuca.

Centro de Investigaciones y Estudios Superiores en Antropología Social, Programa Peninsular, Mérida, Yucatán, México.

\section{RESUMEN.}

En el verano de 1833 el cólera llegó a Yucatán, México. En Mérida, la capital de la Península de Yucatán, y en cada pueblo se instaló una junta de sanidad que tomaba las decisiones pertinentes contra la epidemia. En todos los pueblos hubo muertos, salvo en Bolonchenticul (Campeche), donde se aplicaron medidas que algunos vecinos calificaron de arbitrarias y escandalosas, pero que finalmente resultaron efectivas para frenar el mal. Mientras que en otras localidades y en las haciendas morían decenas de personas todos los días, en Bolonchenticul se llevaba a cabo una lucha de poder local, que iba más allá del bienestar del pueblo. Así en este trabajo, esbozaremos la situación del cólera en 1833 en la Península de Yucatán y nos enfocaremos en el caso de Bolochenticul tanto para analizar las medidas locales contra la enfermedad, como para examinar las pugnas internas de poder que llegan a su punto más álgido en situaciones extremas, como una epidemia. (Rev Biomed 2006; 17:140-145)

Palabras clave: Yucatán, cólera, historia de la medicina, Boloncheticul Campeche.

\section{SUMMARY.}

Control and power during a period of disease. The 1833 cholera morbus in Bolonchenticul village, Yucatan Peninsula, Mexico.

During the summer of 1833, cholera reached Yucatan Mexico. In Mérida, the chapitol of the Yucatan Peninsula, and in every village a health committee was installed to make the appropriate decisions against the epidemic. In all the villages there were deaths, except in Bolonchenticul (Campeche), where the authorities applied measures considered to be shocking and arbitrary, by the neighbours but were finally effective against cholera. While in other villages and farms people died every day, in Bolonchenticul a local power

Solicitud de sobretiros: Dra. Laura Machuca, Centro de Investigaciones y Estudios Superiores en Antropología Social, Programa Peninsular, Calle 49 No. 489-B entre 58 y 60, C.P. 97000, Mérida, Yucatán, México.

Tel.9234813 Fax.923 7243 Correo electrónico: laurama@ciesas.edu.mx

Recibido el 31/Marzo/2006. Aceptado para publicación el 11/Mayo/2006.

Este artículo está disponible en http://www.uady.mx/sitios/biomedic/revbiomed/pdf/rb061728.pdf

Vol. 17/No. 2/Abril-Junio, 2006 


\section{Machuca.}

struggle took place exceeding the community wellbeing. In this work, we outline the 1833 cholera situation in the Yucatan peninsula and we focus on the Bolonchenticul case to analyze local measures against the disease and to examine the domestic conflict of power that reaches a critical point in extreme situations, such as during an epidemic. (Rev Biomed 2006; 17:140-145)

Key words: Yucatan, cholera, history of medicine, Bolonchenticul Campeche.

\section{INTRODUCCIÓN.}

En el verano de 1833, el "temible mal devorador”, como los contemporáneos llamaron al cólera, llegó a Yucatán. Aunque se aplicaron las mayores medidas sanitarias, la mortandad fue alta y sólo un pueblo en toda le península se salvó de ser contagiado: Bolonchenticul (Campeche). Ahí las disposiciones para combatir la epidemia a pesar de ser efectivas, causaron gran disgusto entre algunos vecinos. De hecho, la epidemia fue el detonador para que los grupos en pugna (representados por dos personas, ambos políticos y hacendados), intentaran imponer su autoridad. En este trabajo estudiaremos tanto las medidas que se tomaron para combatir el cólera, como la lucha de poder que se llevaba a cabo en Bolonchenticul.

\section{EL CÓLERA EN YUCATÁN.}

1833 se recordará en Yucatán por dos acontecimientos: por haber sido año de elecciones, en que ganaron los federalistas después de la experiencia centralista de 1829 a 1832, y por el cólera. El azote devorador o cólera morbo era una infección intestinal acompañada de vómitos, diarreas y deshidratación lo que llevaba a una muerte rápida. Como es sabido, la epidemia había salido de la India desde 1817 y se había propagado poco a poco por todo el mundo. En Nueva York apareció en agosto de 1832, a Tampico llegó el 2 de marzo de 1833, a Campeche el 24 de junio y el 10 de julio a Mérida $(1,2)$.

Como lo han mostrado varios autores, esta epidemia afectó con mayor violencia a los asentamientos urbanos, donde imperaban las peores condiciones de higiene y pobreza $(1,2)$. En Yucatán, desde 1813 se había creado una Junta General de Sanidad para velar por la salud pública, que a principios de junio de 1832 emitió un dictamen sobre la epidemia que se acercaba. Se planteó la cuarentena a que debían sujetarse las embarcaciones antes de tocar suelo yucateco, y la instalación de dos comisiones, una en Mérida y otra en Campeche, que se encargarían de revisar la legislación, de enterarse de las novedades de la enfermedad, de imponer las medidas necesarias para precaver el contagio o combatir el mal, y que el gobierno se encargaría de difundir (3).

El gobernador José Tiburcio López, ante la noticia de que los síntomas del cólera se dejaban sentir en Campeche, ordenó una serie de medidas para evitar su expansión. Entre ellas figuraba que a un cuarto de legua de los pueblos no infestados debían construirse algunas casas, para que ahí se quedara toda la gente que viniera de fuera (presumiblemente de pueblos infectados) y los guardias. Asimismo, los atacados de cólera dentro de los pueblos debían ser conducidos a estas casas (4).

En Mérida, el ayuntamiento publicó el 29 de junio las siguientes medidas: conservar aseadas las calles, absteniéndose de arrojar aguas corrompidas u otras inmundicias que infestaran el aire. Como la ciudad se dividió en 4 cuarteles, la basura se tiraría en los puntos indicados para cada lugar. En el basurero general sólo se arrojarían los restos de las fábricas de aguardientes y los animales muertos. Se autorizaba a prender hogueras, aunque fueran de basura, en las puertas de las casas y en los patios (cuidando de no crear un incendio) para purificar la atmósfera, pues se creía que la enfermedad podía contagiarse en el medio ambiente (5). Además se recomendó emplear sal común en los pisos y lugares que fueran foco de infección y usar cal como sudorífico al manifestarse la enfermedad (6).

Sin embargo, parece que en los pueblos

\section{Revista Biomédica}




\section{El cólera de 1833 y el pueblo de Bolonchenticul, Yucatán.}

y en las haciendas, debido a su lejanía, fue más difícil hacer cumplir las medidas, sobre todo la gente maya se resistía a enterrar a los muertos sin velarlos (ya que el vibrión colérico se conservaba en el cuerpo unos días después del deceso), desconfiaba de las medicinas y no seguía las dietas recomendadas (6). En otros trabajos ya se ha hecho alusión a los tratamientos y medicamentos usados para tratar el cólera en el país y en Yucatán. Baste mencionar que en Mérida, el Dr. Ignacio Vado Lugo, fundador de la escuela de Medicina en 1833, recomendó tomar agua fresca, para provocar el vómito e hidratar, volviéndose un pionero de la hidratación oral. En los pueblos, se hizo uso de los recursos naturales locales, se daba a los enfermos infusiones de hojas de naranjas agrias e incluso chile habanero con sal "para el vómito de sangre”, a pesar de que en Puebla, por ejemplo, se recomendaba evitar el chile y otras especias (1, 2, 7, 8).

\section{EL CASO DE BOLONCHENTICUL.}

A continuación, analizaremos el caso de Bolonchenticul, que involucra a dos bandos contrarios, cada uno con su cabecilla. Por un lado, Julián Molina y Bastante, quien fue abuelo del poderoso Olegario Molina, gobernador de Yucatán durante el régimen de Díaz. Los hermanos Martínez, por otro lado, eran unos vecinos de Campeche, que se habían trasladado a Bolonchén buscando fortuna. Santiago fungía como alcalde conciliador y su hermano Anastasio como comandante militar (9).

Tras la llegada del cólera a la península, en Bolonchenticul el 7 de julio, se formó una junta de sanidad compuesta por los vecinos más prominentes. Ellos tomaron una serie de medidas, como la de prohibir a toda clase de personas salir fuera de los límites de la administración del pueblo, también decidieron que:

"...teniendo en consideración que el humo y aromas disipan el influjo del aire infecto, acordó que en todas las puertas de las casas se quemen palos verdes y hierbas aromáticas y que para el mismo efecto se paguen dos individuos en cada cabo del pueblo, para que ellos enciendan hoguerones de la especie indicada, de las cuatro de la tarde hasta la media noche. Cuyo pago saldría de entre los vecinos en calidad de reintegro y que los individuos de la audiencia sean obligados a encender desde la misma hora las hogueras necesarias en la plaza.

2. Siendo útiles los efectos de la cal para evitar la peste se lechen las casas por dentro y fuera, que los suelos de estas sean regados con cal...

3. Que no se permitan haigan(!) velorios poniendo al efecto los celadores necesarios.

4. Que se procure haiga(!) la carne fresca todos los días o por lo menos tres en la semana para cuyo efecto se invitarán a los abastecedores..." (10).

El 10 de julio la misma junta acordó se pusiesen las guardias y custodias necesarias en todos los caminos, con el objeto de evitar toda clase de comunicación con los lugares infestados y los que quisieran residir o establecerse en el pueblo tenían que esperar diez días a las afueras, hasta que comprobado que estaba sano se le diera un pase de introducción. Sin embargo, conforme los días transcurrieron se volvieron más estrictos y después definitivamente sólo entró muy contada gente. También tenían la intención de hacer traer un médico para que asistiera a los enfermos, cuyo salario se pagaría con la colaboración de los miembros prominentes del pueblo. El 19 de julio recibieron en respuesta de Mérida que no era posible mandar un médico, así que reformaron un poco las medidas y ordenaron que se continuaran con las hogueras acordadas, pero en lugar de ponerlas en los cabos del pueblo, se haría sólo una en la plaza. Además se nombrarían cuatro individuos para que se mantuvieran de pie frente a la casa consistorial para detectar cualquier persona infectada (10).

Estas medidas y otras que referiremos más adelante causaron gran disgusto entre algunos vecinos, quienes se quejaban de la conducta dictatorial del jefe político Martínez, a quien 


\section{Machuca.}

acusaban, junto con su hermano Anastasio y el vocal José María Esquivel, de haber formado un consejo de guerra que castigaba con azotes y cepo a todo aquel que desobedeciera sus órdenes. Julián Molina decía de Martínez que estaba aplicando con el mayor rigor la incomunicación del pueblo, infringiendo así graves perjuicios a los comerciantes que ya no podían entrar a vender y a los habitantes que no podían adquirir ningún producto ni recibir ayuda espiritual. Incluso se llegó al punto de que el sacerdote tuvo que bautizar en el cabo del pueblo a un bebé de los ranchos, por prohibir la entrada a los padres. Estos mismos indígenas de los ranchos Cun y Kachech, al no poder entrar a Bolonchen a comprar fueron a Sacabchen, pescando la enfermedad y llevándola a sus casas. A los del pueblo que poseían milpas sólo se les dejaba salir con una papeleta, la cual debían mostrar al regreso so pena de no volver entrar. Molina pedía al gobernador que se permitiera toda clase de auxilios a los habitantes de los ranchos para que la enfermedad no acabara con ellos. Esta preocupación de Molina no era gratuita, ya que de los ranchos obtenía su mano de obra. En una posterior comunicación agregaba el caso de una mujer, quien al sospecharse estaba atacada de cólera, fue conducida al monte a hacer cuarentena.

De hecho, la cuestión de qué se haría con la gente de los ranchos se había ya planteado desde principios de agosto, sobre todo se temía, como sucedió, que los vecinos podían ir a parajes infectados y luego entrar al pueblo y contagiar la enfermedad, por lo que la junta decidió que en lo sucesivo ya no se permitiría a ningún habitante de los ranchos su entrada, a menos de que se tuviera la certeza que no habían tenido roce con pueblos afectados. Asimismo, cualquier persona que quisiera salir de Bolonchenticul ya sea para sus labores u otros puntos, debía contar con un permiso del alcalde, que obtendría siempre y cuando contara con la garantía de una persona conocida. Por último, los cabos situados en los extremos del pueblo, no debían desamparar su puesto ni para ir a comer, y quien cometiera falta sería castigado con la mayor severidad (10).

$\mathrm{Al}$ enterarse la junta que dos indios de la hacienda Yaxché habían muerto, quienes al parecer se infectaron en Mérida de donde volvían cuando se les encontró -y aunque Molina juraba que la causa de su muerte fue otra- se mandó incomunicarla por 20 días junto con sus poblaciones anexas. Precisamente, fue en las haciendas en que el cólera atacó con más fuerza. Por ejemplo en Hunucmá, en el mes de agosto se informaba que en el pueblo habían pocos casos de cólera, pero en las "haciendas, se ha extendido el mal con toda su fuerza desoladora y no ha podido este cuerpo cerciorarse del número de los muertos por que los mayordomos que tenían la orden de mandar diariamente las listas de los que van enterrados en sus respectivas haciendas, han sido casi los primeros que han fallecido y no han tenido por conveniente mandar a aquella indagación a ninguno de aquí por temer se infecte en su comisión y que a su regreso traiga de nuevo a este pueblo la epidemia”. Y la misma situación se había presentado en Yotholim, Xocneceh y Maní (11).

Para septiembre, la junta de sanidad en Boloncehnticul se había completamente desarticulado, pues Julián Molina y su yerno Antonio Cervera prefirieron separarse, según decía el ayuntamiento por vigilar "sus intereses particulares con su comercio y relaciones a la capital”. Por lo que se decidió organizar una nueva junta integrada por gente del clan de los Martínez. Sin embargo, no deja de llamar la atención que mientras funcionó la junta anterior, todas las medidas que tanto criticaba Julián Molina, él mismo las había firmado. Martínez acusaba a Molina de que "remitiendo momentáneamente a sus sirvientes lo que a la fuerza quieren se comuniquen con los habitantes de esta población, manifestándose con estos hechos inhumanos ser sus miras introducir la epidemia que con tanto trabajo y disgusto se ha precavido, debiendo ser los que debían mirar por el bien común, como una

\section{Revista Biomédica}




\section{El cólera de 1833 y el pueblo de Bolonchenticul, Yucatán.}

de sus primeras atenciones” (10).

En una de las últimas acciones de la junta, a fines de septiembre, se dio la orden para asear calles y abrir caminos. Y aunque ya no había dinero para pagar a los cabos, se vuelve a recurrir a la generosidad de los vecinos para que esta medida no se descuidara, "pues tenemos a la vista que otros pueblos por haber franqueado sus comunicaciones han sido devorados por la epidemia”. En adelante sólo sería responsabilidad del alcalde el permiso para que alguien externo al pueblo entrara en él. (10)

La pugna entre Martínez y Molina era sólo política y de poder, ya que Julián Molina quería el predominio local y no le gustaba que otro tomara las riendas. Los hermanos Martínez y José María Esquivel fueron llevados a juicio y relevados de sus puestos, sin embargo fueron favorecidos desde un principio por el fiscal Ignacio Quijano, por haber encontrado varias irregularidades, entre ellas que entre los declarantes se encontraban los mismos acusadores, lo que les hacía entrar en contradicciones. Para el fiscal, más que criminalidad había un "celo incesante y laudable por librar el pueblo de Bolonchenticul de que fuera invadido del terrible azote del cólera”. Por ejemplo, el hecho de poner guardas en los caminos, prohibir la entrada de personas procedentes de puntos infectados y castigar a los soldados que faltaban a su deber, fueron medidas determinadas por la misma junta de sanidad y municipal. En cuanto a los pasaportes que se otorgaban para entrar y salir, el fiscal consideró que fue una buena prevención y que no hay lugar a la queja de que a los criados de Julián Molina se les negaba la entrada al pueblo, pues se probó que los ranchos estaban contagiados. Como tampoco había criminalidad en que el cura bautizara a una criatura en el cabo del pueblo, ni que se llevara a las afueras del pueblo a una mujer con sospechas de tener cólera, "siendo esta una medida saludable y perentoria”. (10)

El fiscal consideró que debía dejarse libres a los acusados, como se hizo el 3 de febrero de 1834, por "haber dictado y sostenido con energía las medidas más eficaces para librar del terrible azote del cólera morbo asiático a una numerosa y apreciable población que se hallaba circunvalada por todos los pueblos vecinos de aquel contagio, consiguiendo como consiguieron que hasta la fecha no les invadiera aquella terrible como temible y desoladora peste...". Se ordenó ponerlos de nuevo en sus destinos y que no se afectara su buen nombre y reputación. De todos los pueblos de la península sólo Bolonchenticul presentó saldo blanco, en los Anales históricos de Campeche se consigna que esta situación se logró gracias a "una rigurosa incomunicación”, al contrario en otros pueblos como Teabo el 90\% de la población murió $(6,12)$.

Mientras que en Guadajalara desapareció el $8.11 \%$ de la población y en Puebla el 10\%, en Yucatán murió cerca de un $11 \%$. En Mérida, la mortandad fue del 11\% (de 38251 habitantes en 1832 murieron 4283), pero en la ciudad de Campeche, en cambio, murieron 6,156 de 22 mil habitantes, es decir una cuarta parte. En total en la península murieron 62833 personas de una población total calculada aproximadamente en 574500 personas $(3,12-15)$.

\section{COLOFÓN.}

Hace algunos años, una de las tesis de Lilia Oliver era que el cólera en Guadalajara mató a los individuos pobres y desempleados de la ciudad, basada en que la muerte afecta en forma desigual a los integrantes de una sociedad. Sin embargo, años más tarde el estudio de Elsa Malvido y Miguel Cuenya, para Puebla, mostraron que era la miseria, pero también la falta de higiene y medidas sanitarias correctas las causantes de la enfermedad, pues en esta ciudad no se salvó ni el gobernador ni altos dignatarios de la iglesia $(1,2)$. El caso de Bolonchenticul nos muestra que con las estrictas medidas que se tomaron -casi dictatoriales y que causaron tanto disgusto entre algunos de sus habitantes- $y$ en realidad con muy poco dinero, sólo para pagar a los guardas y prender las hogueras, se logró alejar una epidemia 


\section{Machuca.}

que prácticamente asoló a todos los pueblos de Yucatán. Con lo que se muestra que lo fundamental no era la pobreza de los habitantes si no las acciones concretas y contundentes en materia de salubridad y protección, ejercidas por los que estaban en el poder.

Este caso también nos ha enseñado que en periodo de epidemias y de crisis, la solidaridad llega hasta el límite que no afecte los intereses personales, pero en el momento que esto llega a suceder, el bienestar colectivo pasa a segundo plano. Julián Molina ejemplifica la situación al tratar de aprovechar esta coyuntura para tratar de desprestigiar a alguien que no lo apoyaba y que mermaba su clientela. Así, salud y poder se conjugan para lograr el bien de la comunidad o el provecho de unos cuantos.

\section{REFERENCIAS.}

1.- Olivier L. "La pandemia del cólera morbos. El caso de Guadalajara, Jal en 1833”. En Florescano E, Malvado E, compiladores. Ensayos sobre la historia de las epidemias en México. 2v. (Colección salud y seguridad social, serie historia). México: IMSS; 1982. p. II, 583-602.

2.- Malvido-Miranda E, Cuenya Mateos M. La epidemia de cólera de 1833 en Puebla. Rev Biomed 1994; 5:220-5.

3.- Osorio y Carvajal R. "Historia de la medicina alopática en la época independiente”. Enciclopedia yucatanense. 4v. México: Gobierno de Yucatán; 1944. p. IV, 285- 341.

4.- Ancona E. Historia de Yucatán. (1 ed. 1878). 4 v. Ed. facsimilar. Mérida: Ediciones de la Universidad de Yucatán; 1978. p. III, 339-341.

5.- Bando del 29 de junio de 1833. En El baluarte de la libertad. Sabatino patriótico de Mérida Yucatán. Julio 6 de 1833.

6.- Rubio Canul M, Tzuc-Canché L. 24 horas para morir: epidemia del Cólera Morbo en Yucatán en 1833. Rev Biomed 1995; 6:102-7.

7.- Laviada-Arrigunaga F, Puga-Navarrete A, Laviada Arrigunaga E. El tratamiento del cólera en el siglo pasado. Rev Biomed 1993; 4:95-8.
8.- Cruz S. Un curioso impreso sobre el cólera (Puebla, 1833). En Florescano Enrique y Elsa Malvido (compiladores). Ensayos sobre la historia de las epidemias en México. 2v. (Colección salud y seguridad social, serie historia). México: IMSS; 1982. p. II, 615-622.

9.- Wells A. Family Elites in a Boom-and-Bust Economy: The Molinas and Peons of Porfirian Yucatán. HAHR 1982; 62 (2):224-53.

10.- AGEY. Poder Ejecutivo. Justicia. Vol. 3 exp. 24. "Averiguación promovida por varios vecinos de Boloncheticul, para esclarecer la culpabilidad de Santiago Martínez alcalde conciliador de dicho pueblo, por malos tratos a los habitantes.” 1833.

11.- AGEY. Poder Ejecutivo. Correspondencia. "Correspondencia de varios funcionarios de los pueblos con el gobernador del estado, con informes de la epidemia del cólera morbos.” Vol. 3 exp. 15. Julio 301833.

12.- Álvarez F. Anales históricos de Campeche. 1812-1910. 2 v. (1 ed. 1912) Ed. facsimilar. Campeche: Ayuntamiento de Campeche, 1991.

13.- Waldeck F. Viaje pintoresco y arqueológico a la provincia de Yucatán, 1834 y 1836. (1 ed. 1838) Trad. Manuel Mestre Ghigliazza. Presentación Hernán Menéndez Rodríguez. México: CONACULTA; 1996.p. 83.

14.- Rodríguez-Losa S. Geografía política de Yucatán. División territorial, gobierno de los pueblos y población 1821-1900. Mérida: Universidad Autónoma de Yucatán; 1989: II.

15.- Laviada-Arrigunaga F, Laviada-Arrigunaga E, PugaNavarrete A. El cólera en la península de Yucatán en el siglo pasado. Rev Biomed 1993; 4:43-8.

\section{Revista Biomédica}

